\title{
THE ROLE OF HUMAN RESOURCE MANAGEMENT IN ROMANIAN PRE-UNIVERSITY EDUCATION DURING THE COVID-19 PANDEMIC
}

\author{
Monica R $\breve{A D U C A N}{ }^{a *}$, Nicoleta CRISTACHE ${ }^{b}$, Cosmin MATIȘ $^{c}$ \\ a, b "Dunărea de Jos" University of Galati, Romania \\ ${ }^{c}$ Babes-Bolyai University, Cluj-Napoca, Romania
}

DOI: $10.24818 / \mathrm{IMC} / 2020 / 04.19$

\begin{abstract}
This research paper approaches the aspects connected to the analysis of the role of human resource management policies in pre-university education system in Romania, in the new paradigm generated by the COVID-19 pandemic. We propose to provide a survey of employees 'perception of HRM by designing SWOT analysis of the Romanian pre-university education system and a questionnaire applied to school managers and teachers from urban and rural, state and private schools in our country. The findings of the present research revealed the fact that teachers and school managers consider HRM educational policies developed during this period responsible for increasing schools and teachers' performance, for strengthening the feeling of stability and predictability of the educational act and also for improving the social perception of the teaching profession.
\end{abstract}

KEYWORDS: COVID-19 pandemic, human resources management, pre-university education, SWOT analysis, teachers 'performance.

\section{INTRODUCTION}

In the new and dynamic paradigm, generated by the coronavirus pandemic, education systems must face a new type of challenge, starting with the strategic government policies concerning human resource management and continuing with their effective implementing. At the systemic and institutional level, it is recommended to redesign the entire human capital system, so as to ensure the employees who are strategically placed and fairly distributed in schools, and also to guarantee equity and equal opportunities in terms of access to education for all students.

\section{THE ROLE OF HUMAN RESOURCE MANAGEMENTIN THE PRE-UNIVERSITY EDUCATION SYSTEM DURING COVID-19 PANDEMIC}

One of the issues of permanent relevance, faced by the Romanian pre-university education, is represented by the human resource considered as a main actor in building a sustainable democratic society and the most valuable resource within any educational institution.

The drawbacks generated by COVID-19 related to human resource management refers to the changes in communication channels: for instance, "the pandemic has made the decision-making slow because meetings and schedules are not every time aligned with each other. Therefore, in the absence of signatories, resolutions must be made” (De Leon, 2020).

\footnotetext{
* Corresponding author. E-mail address: monica.raducan@ugal.ro
} 
Thus, the role of Human Resource Management in schools consists in:

- implementing free training programs for online teaching which can be accessible to all teachers

- identifying workforce needs of the schools

- recruiting and managing employees accordingly

- ensuring the availability and continuity of the labor force

- a new leadership style, adapted to motivating teaching staff in an online learning format

- keeping key-employees in the system

- preventing dropouts

- developing new skills and competencies: hard skills and soft skills

- providing medium- and long-term solutions for teaching, learning and evaluating students

- ensuring healthy parameters for school re-opening

- Designing wellbeing programs for employees, in order to prevent teachers 'burnout.

At the end of 2019-2020 school year, the impact of the pandemic on the education system, respectively on the performance of all the actors in the system, could be registered on the following aspects:

- students' participation in online educational activities depending on their access to the internet, the existence of electronic devices, and the involvement of the family in accessing lessons and learning resources provided by teachers.

- elements of academic performance at the level of the pre-university education system: the results registered at:

- National Evaluation: out of the 160,663 candidates who were present, a total number of122,357 candidates obtained averages greater than or equal to 5 (76.20\% of the total), while 892 candidates registered the overall average 10 .

- Baccalaureate: out of 155,639 registered candidates, 64.5\% promoted, while 307 graduates registered the overall average 10 , the best results in the last 16 school years.

In the past eight months of pandemic, the upper management from Romanian Ministry of Education and Research initiated and implemented a series of important measures for the pre-university education system, especially related to:

- measures to prevent SARS-CoV-2 disease in pre-university education institutions

- elaborating procedures for the processing of personal data of the participants in the activities carried out through technology and the Internet

- providing resources for adapting to online learning, for each subject posted on http://educatiacontinua.edu.ro, where teachers benefit from information and tutorials for organizing the online teaching-assessment process;

- Infrastructure and devices supply for online teaching. As schools were forced to use remote teaching for the first time, HR professionals had to improvise, in order to provide a coherent vision of education.

Even though in the first weeks of the pandemic there were no official practical measures transmitted from the ministry, the pressure was more intense on behalf of middle and lower management, school managers needing to find solutions for continuing teaching (finding devices, educational platforms and organizing teachers and students 'learning activity in crisis circumstances.)

On the other hand, this period represented a good opportunity for teachers to improve their teaching methods, adapting them to remote teaching, learning and evaluating (attending training courses, discovering online instruments, education platforms and materials and keeping students connected to school life) and also enhancing innovation and creativity through the development of a learning community. "More important than training teachers in ICT skills, is ensuring that they have the assessment and pedagogical skills to meet students at their level and to implement the accelerated 
curricula and differentiated learning strategies likely to emerge in the return to school" (United Nations, 2020).

Strielkowski (2020) observes that "social distancing and quarantine lockdowns might help the majority of academics and researchers to complete the transition not only to the online education, but also to the online defenses, online entrance exams, and perhaps even online jobs".

Consequently, Nisha (2020), remarks that "the rise of e-learning is quite visible, whereby teaching is undertaken remotely on digital platforms. Technology is shaping and directing the education sector today."

\subsection{SWOT analysis of the pre-university education system in Romania}

Figure 1 contains a comprehensive SWOT analysis of the pre-university education system in Romania.

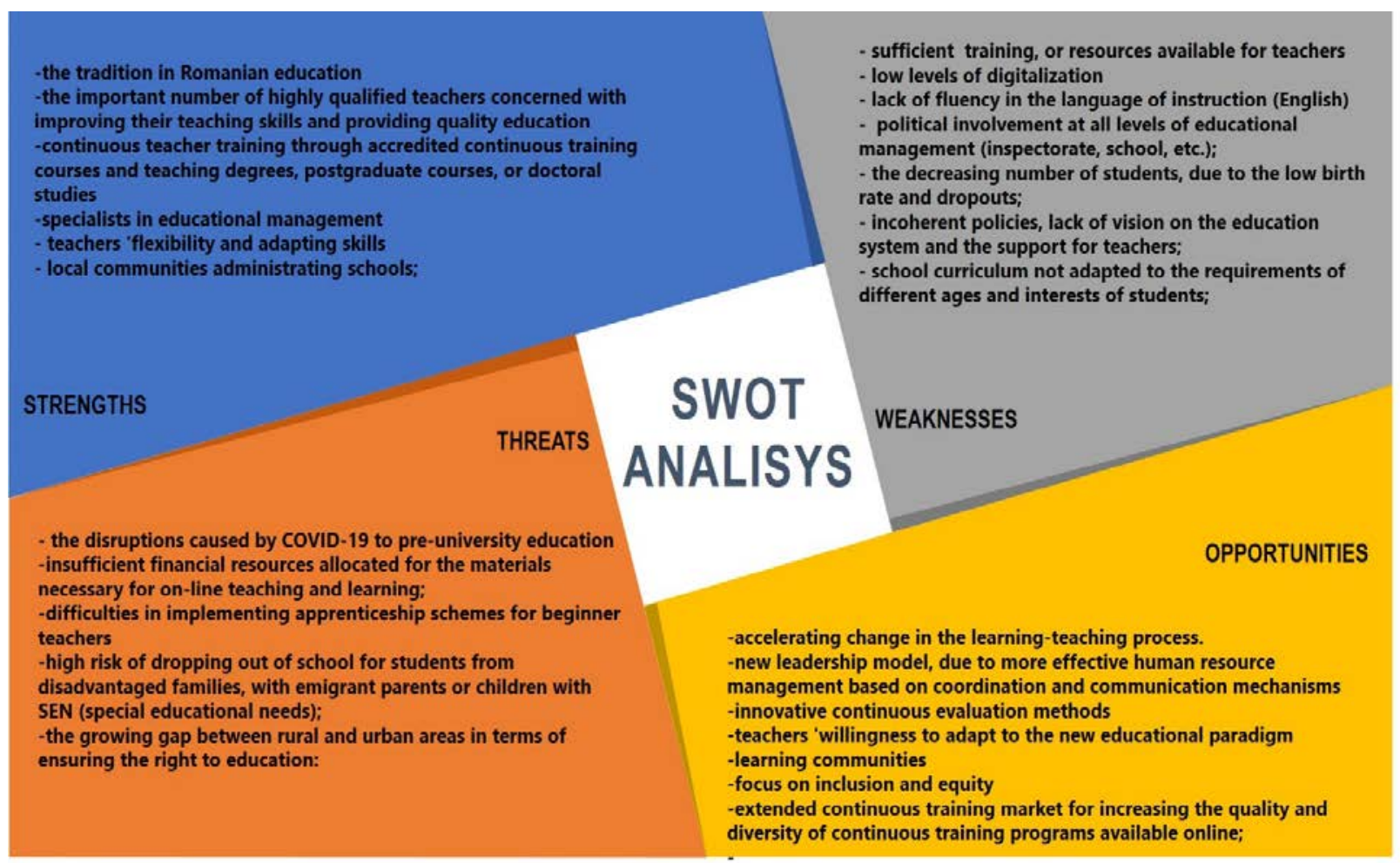

Figure 1. SWOT Analysis

Source: authors processing

The general objective of this research paper was to conduct a study on the role of human resource management policies at the level of pre-university education institutions in Romania, looking to evaluate the field of HRM and to provide insight on the positive aspects, along with those that can be improved, but also ways to investigate the role of human resource management in the new educational paradigm generated by the pandemic.

Research objectives:

- identifying the role of human resources management for the schools' performance;

- identifying the role of human resources management for teachers' performance;

- identifying the role of human resources management for students' performance;

The bibliographic study and the questionnaires applied to teachers and school managers in Romanian education represented the way data were collected. 


\section{RESEARCH METHODOLOGY}

Throughout March and April 2020, a pilot research was designed and carried out. 130 teachers and school managers from rural and urban education institutions in Romania participated. The research tool was a questionnaire, which was sent to the subjects in printed format and / or distributed online, together with a confidentiality statement and a letter of intent.

20 questions were included in the questionnaire which was structured in two parts. Two questions were selected for this research, being addressed both to teachers and school managers in Romania participating in the study, and for each one a table with the global score was designed.

\subsection{The investigated sample}

The sample of respondents at national level is represented by:

- school managers from both urban and rural, state and private pre-university education institutions;

- beginner teachers which attended the Program for the training of beginner teachers of English and French in order to take the final exam in education, organized by the House of the Teaching Staff where I was a trainer;

- teachers of different specializations to whom I collaborated throughout the teaching activity;

- school managers and teachers from the Aspire Teachers Academy, where I am a member;

\subsection{Analysis and interpretation of results}

In addressing the research objectives, this section includes the results and findings (Figure 2, Figure 3 , Table 1 and Table 2) generated by the questions under analysis, which aimed at the solutions and benefits offered by a successful human resources management for a series of defining aspects for the pre-university education system, such as:

- improving the social perception of the teaching profession, especially in the context of the pandemic, when mass-media's attention is oriented towards education field

- better collaboration with the local community and educational partners

- increasing the degree of involvement of the teacher in the teaching process

- strengthening the feeling of stability and predictability of the educational act, by ensuring strong leadership and coordination from all management levels

- promoting fair competition among employees.

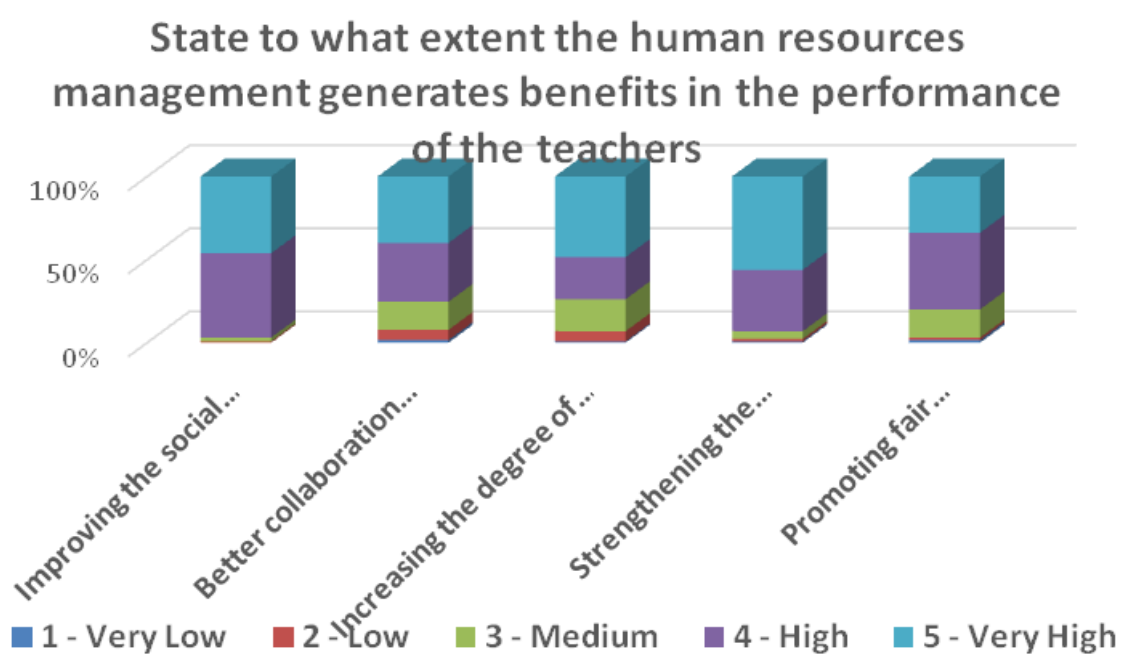

Figure 2. Analysis of the answers offered by teachers in Romania Source: authors processing 
Table 1. Overall score of the results recorded after processing the questionnaires of the Romanian respondents

\begin{tabular}{|c|c|c|c|c|c|c|c|c|c|c|}
\hline & $\begin{array}{l}\text { Improving } \\
\text { the social } \\
\text { perception } \\
\text { of the teaching } \\
\text { profession }\end{array}$ & $\begin{array}{c}\text { Better } \\
\text { collaboration } \\
\text { with the local } \\
\text { community/ } \\
\text { educational } \\
\text { partners }\end{array}$ & $\begin{array}{c}\text { Increasing } \\
\text { the degree } \\
\text { of involvement } \\
\text { of the teacher } \\
\text { in the teaching } \\
\text { process }\end{array}$ & $\begin{array}{l}\text { Strengthening the } \\
\text { feeling of stability } \\
\text { and predictability } \\
\text { of the educational } \\
\text { act }\end{array}$ & $\begin{array}{l}\text { Promoting } \\
\text { fair } \\
\text { competition }\end{array}$ & & & & & \\
\hline I - Vегу Low & 0 & 2 & 1 & 1 & 2 & 0 & -4 & -2 & -2 & -4 \\
\hline Z - Law & 1 & 8 & 8 & 2 & 2 & -1 & -8 & -8 & -2 & -2 \\
\hline 3 - Medium & 3 & 22 & 25 & 6 & 22 & 0 & 0 & 0 & 0 & 0 \\
\hline 4 - High & 66 & 46 & 33 & 48 & 60 & 66 & 46 & 33 & 48 & 60 \\
\hline \multirow[t]{2}{*}{5 - Very High } & 60 & 52 & 63 & 73 & 44 & 120 & 104 & 126 & 146 & 88 \\
\hline & & & & & & 1,42 & 1,06 & 1,15 & 1,46 & 1,09 \\
\hline
\end{tabular}

Source: authors processing

According to the answers received from teachers in Romania for the first question, related to the benefits generated by the human resource management in the performance of teachers, it was observed that a significant percentage of the total number of respondents is registered in "Very High" (60) "High" (66) for improving the social perception for the teachers 'profession.

For the collaboration with local community and educational partners, the scores registered are "Very High" (52) and "High" (46), which allows us to note that both are considered as direct results of a successful human resources management.

The role of the HRM in increasing the degree of involvement of the teacher in the teaching process during this new educational paradigm is perceived as "Very High" (63) and "High" (33), as well as in strengthening the feeling of stability and predictability of the educational act, for 73 respondents with the highest score. Employees in educational sector need to perceive the organizational culture as being a part of a coherent set of policies and long-term strategies, regarding especially human resource management, such as: recruitment and staffing strategies, developing and training, motivating and maintaining valuable teachers within the system.

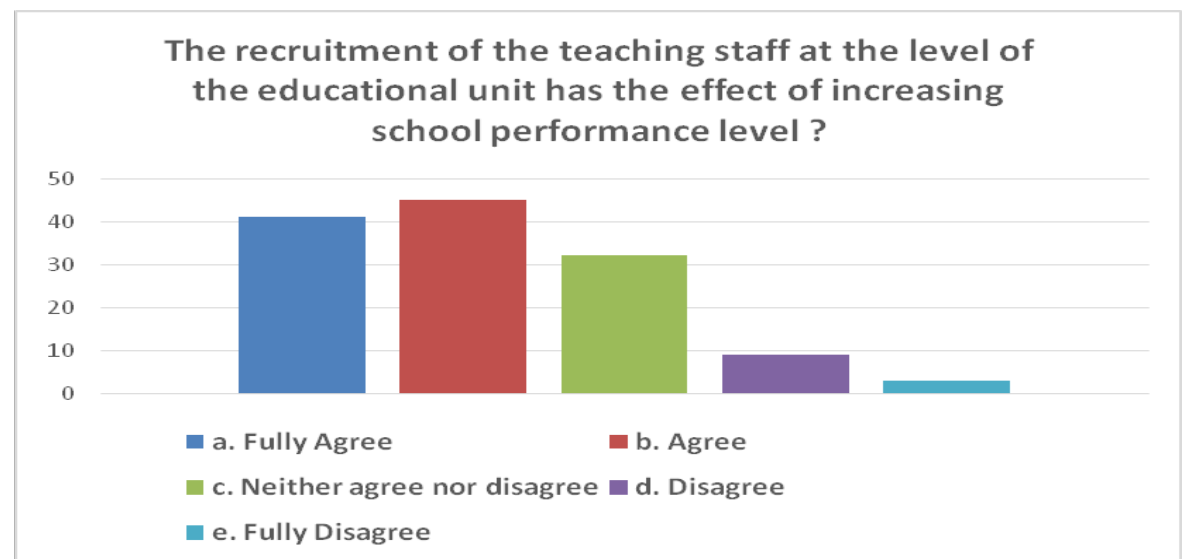

Figure 3. Analysis of the answers offered by teachers in Romania Source: authors processing

Table 2. Overall score of the results recorded after processing the questionnaires of the Romanian respondents 


\begin{tabular}{|l|r|r|}
\hline & \multicolumn{1}{|c|}{$\begin{array}{c}\text { The recruitment } \\
\text { of the teaching staff } \\
\text { at the level of the educational unit } \\
\text { has the effect of increasing } \\
\text { school performance level? }\end{array}$} & \\
\hline a. Fully Agree & 41 & 82 \\
\hline b. Agree & 45 & 45 \\
\hline c. Neither agree nor disagree & 32 & 0 \\
\hline d. Disagree & 9 & -9 \\
\hline e. Fully Disagree & 3 & -6 \\
\hline & & $\mathbf{0 , 8 6}$ \\
\hline
\end{tabular}

Source: authors processing

The second question referred to the recruitment of the teaching staff at the level of the school and its effects on school performance level.

The significant number of answers "Fully Agree" - 41 and "Agree" - 45 indicates the fact that the school performance level in Romania is conditioned and directly influenced by aspects related especially to strategic management, such as the recruitment of the teaching staff at the level of the educational unit, according to its specific features and requirements.

At the same time, 32 answers "Neither Agree nor Disagree" imply the idea that school autonomy in the staff recruitment issue is not always recommended because it often interferes with different political interests which can and will undoubtedly affect schools 'performance.

\section{CONCLUSIONS}

Analyzing the Romanian pre-university education system, from the perspective of human resource management, we can notice its impact upon the performance of teachers and schools, too.

Therefore, it is imperative for human resource management in pre-university education institutions to re-imagine education and to adapt to latest challenges and changes in the way quality education is being delivered, in order to prevent a learning crisis with long-term effects.

All things considered, in the face of the changes imposed by the new educational paradigm generated by the pandemic, the role of HRM in pre-university education institutions is to show an increased interest in focusing on equity and inclusion, while continuously reinforcing capacities for risk management.

Furthermore, future research based on this study needs to advance the analysis of the impact of human resource management policies on teachers' motivation and performance, from the perspective of improving educational efficiency and equity in schools.

\section{REFERENCES}

De Leon, Z. (2020). Human Resource Management: Valued or Devalued under the Pandemic, from https://www.academia.edu/44215366/HUMAN_RESOURCE_MANAGEMENT_VALUED_OR_DEV ALUED_UNDER_THE_PANDEMIC

Nisha, P. R. (2020). COVID-19 Pandemic: Smart Use of Technology Needed in Education, from https://www.academia.edu/43460749/COVID_19_pandemic_Smart_use_of_technology_needed_in_edu cation.

Strielkowski, W (2020). How Can the COVID-19 Pandemic Help Higher Education, from https://www.academia.edu/42700840/How_can_the_COVID_19_pandemic_help_higher_education.

United Nations. (2020). Policy Brief: Education during COVID-19 and beyond, from https://www.un.org/development/desa/dspd/wpcontent/uploads/sites/22/2020/08/sg_policy_brief_covid19_and_education_august_2020.pdf. 